\title{
A Comparative Study of Behavior of Multi-Storied Regular and Irregular Buildings under Static and Dynamic Loading
}

\author{
Swagato Biswas Ankon \\ Department of Civil Engineering, Rajshahi University of Engineering \& Technology, Rajshahi, Bangladesh \\ Email: ankonbiswas62@gmail.com
}

How to cite this paper: Ankon, S.B. (2020) A Comparative Study of Behavior of Multi-Storied Regular and Irregular Buildings under Static and Dynamic Loading. Open Journal of Civil Engineering, 10, 337-352. https://doi.org/10.4236/ojce.2020.104026

Received: October 18, 2020

Accepted: December 8, 2020

Published: December 11, 2020

Copyright (๑) 2020 by author(s) and Scientific Research Publishing Inc. This work is licensed under the Creative Commons Attribution International License (CC BY 4.0).

http://creativecommons.org/licenses/by/4.0/

\section{(c) (i) Open Access}

\begin{abstract}
One of the major challenges of constructing any high rise building for civil engineers is to make it earthquake resistant. This resistance largely depends on the building's shape and structural system. A comparative study has been done in this paper about the seismic behavior and response of buildings having a regular plan and plan irregularity (re-entrant corners). The 5 building models considered in this study are 15 stories each, the same area and identical weight. Among the 5 building models, 2 are with a regular plan (square, rectangle) and the other 3 building models are with plan irregularity (re-entrant corners). All of them are modeled using ETABS 2015 program for Dhaka, Bangladesh (seismic zone 2). Static loads, wind loads and seismic loads are considered for each model and dynamic response under Bangladesh National Building Code (BNBC) 2006 response spectrum has been meticulously analyzed. A comparison for story displacement, base shear, story drift and time period has been established and explored for dynamic response spectrum among the models. The results show that buildings with irregularity have a greater value of time period, drift and displacement and hereby are more susceptible to damage during an earthquake or disaster.
\end{abstract}

\section{Keywords}

Response Spectrum Method, Regular Plan and Plan Irregularity, Re-Entrant Corners, Story Displacement, Base Shear

\section{Introduction}

Bangladesh, a South Asian country is located at the junction point of three tectonically active regions [1]. It is situated where three tectonic plates meet: The Indian plate, The Eurasian Plate and The Burmese plate. The Indian plate is 
moving northeast slowly colliding with The Eurasian Plate. On the other hand, The Burmese plate pushes west against The Indian plate. That is why a significant amount of earthquakes have hit this area in the historical past and scientists believe that a major earthquake in this region is only a matter of time. With over 21 million people living in this city, more than 23,000 people living per square kilometers, the megacity Dhaka is at the greatest risk [2]. Although Dhaka city has experienced some mild and a few moderate earthquakes on an average of 5 on the Richter scale, it is a clear indication of its vulnerability and susceptibility to greater earthquakes. In the recent past, an earthquake of 5.9 on the Richter scale was experienced on the $16^{\text {th }}$ of April, 2020 originating in Myanmar [3]. The Earthquake Disaster Index has enlisted Dhaka as one of the 20 most vulnerable cities in the world [4]. Earthquakes can indulge critical stress to the structure which can result in excessive lateral sway or even failure of the structure. For these reasons, dynamic response is an essential element to be considered for the design of any building structure. The main objective is to survive and keep the structure serviceable after the disaster.

In a study, Ravikumar, C. et al. (2012) showed the structural performances of different irregular buildings in rocky soil in India [5]. In another study, M. Kabir et al. (2015) discussed the response of multistoried RC building in context of Bangladesh [6]. Equivalent static and response spectrum analyses were carried out for 3 regular and 1 irregular building models but re-entrant corner irregularity was not considered in their study. M. Haque et al. (2016) analyzed the seismic performance of multistoried RC building with plan irregularity in their study [7]. Equivalent static, time history and response spectrum analysis were carried out using ETABS 9.7.1 and SAP 2000 v14.0.0 for W shaped, L shaped, rectangular and square building models considering the equal span of each frame but not the same area and identical mass. M. A. Farhan and J. Bomisetty (2019) discussed the seismic analysis of multistoried RC building considering regular and irregular plan having re-entrant corners [8]. A comparison for story displacement and base shear was shown among rectangular, $\mathrm{C}$ shaped, $\mathrm{T}$ shaped and I shaped building. M. Firoz and S.K. Singh discussed the response spectrum analysis of an irregular multistoried building in seismic zone $\mathrm{V}$ in their study [9]. One irregular building $(\mathrm{G}+9)$ was taken and analyzed through ETABS, STADPRO and SAP2000. Joint displacements, axial forces, time period and mass participating factors were studied meticulously.

The shape of a building and its regularity both vertically and plan wise plays a vital role in the response of the structure under static and dynamic loading which affects the damages the building would be subjected to during an earthquake. Considering all these factors, 5 building models situated in Dhaka, Bangladesh, 2 of them are regular in shape and the other 3 (L shape, T shape and + shape) having plan irregularity (re-entrant corners) are subjected to static and dynamic loading and are studied. All five models are of the same area and identical weight. Difference in response of each model is observed. 


\section{Plan Irregularity}

Two kinds of irregularities may exist in a building-Plan irregularity and vertical irregularity [10]. Irregularity in which seismic response is tensional and is a result of mass or stiffness eccentricity is regarded as plan irregularity [8]. Plan irregularities can be of five types [10]. They are discussed in Table 1 .

Re-entrant corner irregularity is one of the most common phenomena seen in a structure due to shape of the land of the owner, aesthetical point of view and less consciousness by professionals during designing. That is why, in this paper, building plans with Re-entrant corners are taken into account for comparison with regular building plans. Figure 1 shows the detailed information of buildings having re-entrant corner irregularity.

Table 1. Types of plan irregularities according to Bangladesh national building code 2006.

\begin{tabular}{|c|c|c|}
\hline Type & Definition & $\begin{array}{l}\text { BNBC } 2006 \\
\text { reference section }\end{array}$ \\
\hline 1) Tortinal irregularity & $\begin{array}{l}\text { Torsional irregularity shall be considered to exist when } \\
\text { the maximum story drift, computed including } \\
\text { accidental torsion, at one end of the structure transverse } \\
\text { to an axis is more than } 1.2 \text { times the average of the story } \\
\text { drifts of the two ends of the structure. }\end{array}$ & $\begin{array}{c}\text { 1.5.4.2, } \\
\text { 2.5.6.5, } \\
\text { 1.5.4.3, } \\
1.7 .2 .9(\mathrm{~d})\end{array}$ \\
\hline 2) Re-entrant corners & $\begin{array}{l}\text { Plan configuration of a structure and its lateral force } \\
\text { resisting system contains re-entrant corners, where } \\
\text { both projections of a structure beyond a re-entrant } \\
\text { corner are greater than } 15 \% \text { of the plan dimension in } \\
\text { the given direction. }\end{array}$ & $1.7 .2 .9(\mathrm{~d})$ \\
\hline $\begin{array}{l}\text { 3) Diaphragm } \\
\text { discontinuity }\end{array}$ & $\begin{array}{l}\text { Diaphragms with abrupt discontinuities or variations in } \\
\text { stiffness, including those having cutout or open areas } \\
\text { greater than } 50 \% \text { of the gross enclosed area of the } \\
\text { diaphragm or changes in effective diaphragm stiffness } \\
\text { of more than } 50 \% \text { from one story to the next. }\end{array}$ & $1.7 .2 .9(\mathrm{~d})$ \\
\hline 4) Out-of-plane offsets & $\begin{array}{l}\text { Discontinuities in a lateral force path, such as } \\
\text { out-of-plane offsets of the vertical element. }\end{array}$ & $\begin{array}{c}1.5 .5 \\
1.7 .2 .9(\mathrm{~d})\end{array}$ \\
\hline 5) Nonparallel systems & $\begin{array}{l}\text { The vertical lateral load-resisting elements are no } \\
\text { parallel to or symmetric about the major orthogonal } \\
\text { axes of the lateral force-resisting system. }\end{array}$ & 1.5.4.2 \\
\hline
\end{tabular}

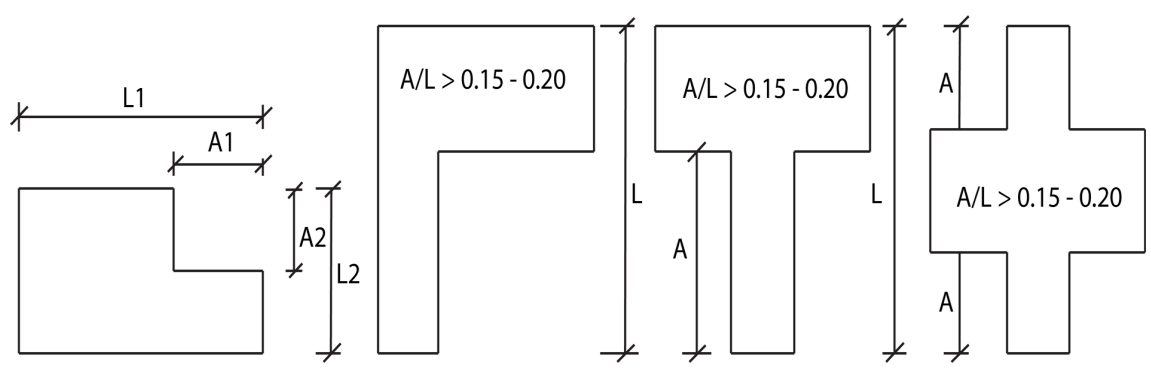

Figure 1. Re-entrant corner irregularity

(fig. 2.5.4b, Bangladesh National Building Code (BNBC) 2014). 


\section{Methods of Analysis}

The analysis has been done by using two methods-Equivalent static method and response spectrum analysis.

\subsection{Equivalent Static Method}

Equivalent static analysis is also known as linear static analysis and can be used only for regular structures with a limited height. It is the simplest form of analysis as it assumes that the building responds in its fundamental mode following the respective code of practice. The design base shear is determined and is then distributed to the height of the building. The lateral forces at each story are also computed and then distributed to the force resisting elements.

\subsection{Response Spectrum Analysis}

It is also known as linear dynamic analysis. According to Section 2.5.7.2, Bangladesh National Building Code 2006, when this procedure is used, an elastic dynamic analysis of a structure shall be performed based on a criterion with a mathematical model and using a response spectrum. The analysis shall include peak dynamic response of all modes having a significant contribution to total structural response. Peak modal response shall be calculated using the ordinates of the appropriate response spectrum curve which corresponds to the modal periods. The number of modes is satisfactory when at least $90 \%$ of the participating mass is included in the response for each principal horizontal direction. The analysis should be performed using a mathematical model either by using site-specific response spectra or normalized response spectra. In absence of a site specific response spectrum, normalized response spectra should be used. In this paper, the normalized response spectra for $5 \%$ damping ratio (Zone 2) mentioned in BNBC 2006 is used for analysis (Figure 2).

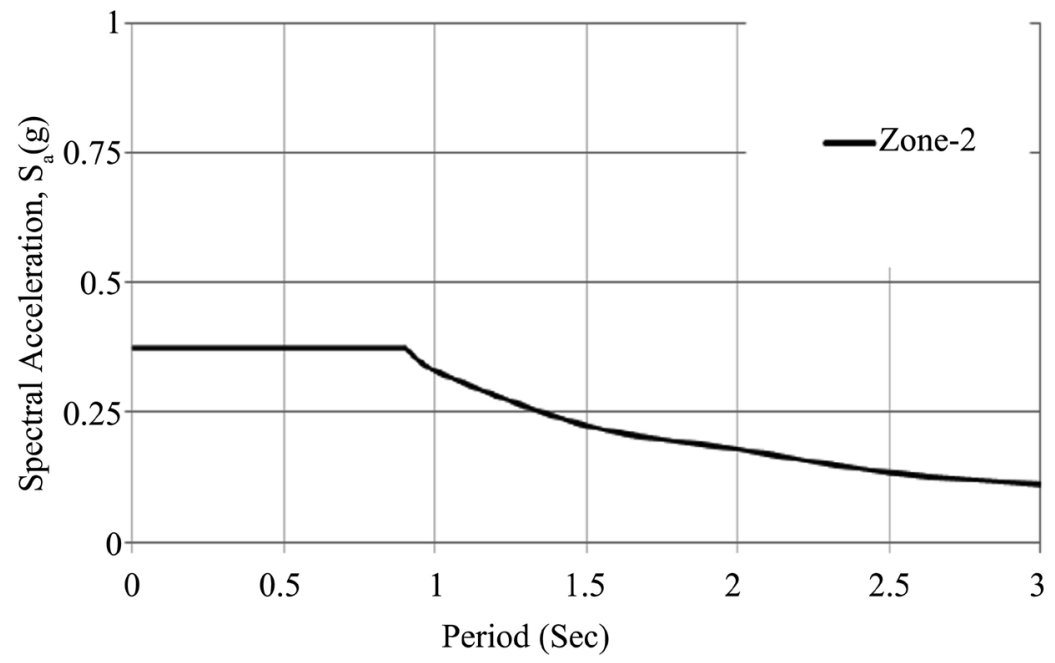

Figure 2. Normalized response spectrum curve for $5 \%$ damping ratio (fig. 2.6.11, Bangladesh National Building Code (BNBC) 2006). 


\section{Details of Models}

In the present study, 5 building models situated in Dhaka (Seismic Zone 2) are taken. Model 1 and model 2 are of regular shapes (square and rectangular) and models 3, 4 and 5 are of irregular shapes ( $\mathrm{T}$ shape, $\mathrm{L}$ shape and + shape) having re-entrant corner irregularity. Each model has 15 stories. The area and mass of each building are kept identical to have a similar influence. Span lengths along $\mathrm{X}$ and $\mathrm{Y}$ direction may vary to keep the area and mass same. Dead load, Live load, Partition wall load, Earthquake load, Wind load have been applied following the regulations of BNBC 2006. Material properties and structural parameters are given in Table 2 and Table 3 for analysis in ETABS 2015 version.

The plans of models 1, 2, 3, 4 and 5 are shown in Figures 3-7 respectively.

The 3D views of models 1, 2, 3, 4 and 5 are shown in Figures 8-12 respectively.

Table 2. Material properties.

\begin{tabular}{cc}
\hline Materials & Values used (unit) \\
\hline Compressive strength of concrete & $4000 \mathrm{psi}$ \\
Modulus of elasticity of concrete & $3600 \mathrm{ksi}$ \\
Shear modulus of concrete & $1500 \mathrm{ksi}$ \\
Poisson's ratio & 0.2 \\
Unit weight of concrete & $150 \mathrm{pcf}$ \\
Yield stress of steel & $60 \mathrm{ksi}$ \\
\hline
\end{tabular}

Table 3. Parameters considered for structure design.

\begin{tabular}{|c|c|}
\hline Parameters & Value/Type for all models \\
\hline Structure type & RCC building structure \\
\hline Number of stories & 15 \\
\hline Elevation & $165 \mathrm{ft}$ \\
\hline Bottom story height & $10 \mathrm{ft}$ \\
\hline Area & 6400 square $\mathrm{ft}$ \\
\hline Grade Beam & 12 in $\times 12$ in \\
\hline Column & $\begin{array}{c}\text { Variable to adjust mass } \\
27 \text { in } \times 24 \text { in square mode } \\
24 \text { in } \times 21 \text { in rectangular model } \\
24 \text { in } \times 24 \text { in T shaped model } \\
24 \text { in } \times 24 \text { in L shaped model } \\
24 \text { in } \times 24 \text { in }+ \text { shaped model }\end{array}$ \\
\hline Floor Beam & 15 in $\times 15$ in \\
\hline Slab thickness & 6 in \\
\hline Floor finish (Dead load) & $30 \mathrm{psf}$ \\
\hline Partition wall load & $15 \mathrm{psf}$ \\
\hline Live load & $42 \mathrm{psf}$ \\
\hline Seismic Zone & $2(Z=0.15)$ \\
\hline Soil type & $S_{3}(S=1.5)$ \\
\hline Importance factor & 1 \\
\hline Response Reduction factor & 5 \\
\hline $\mathrm{Ct}$ & 0.03 \\
\hline Wind Speed & $131 \mathrm{mph}$ \\
\hline
\end{tabular}




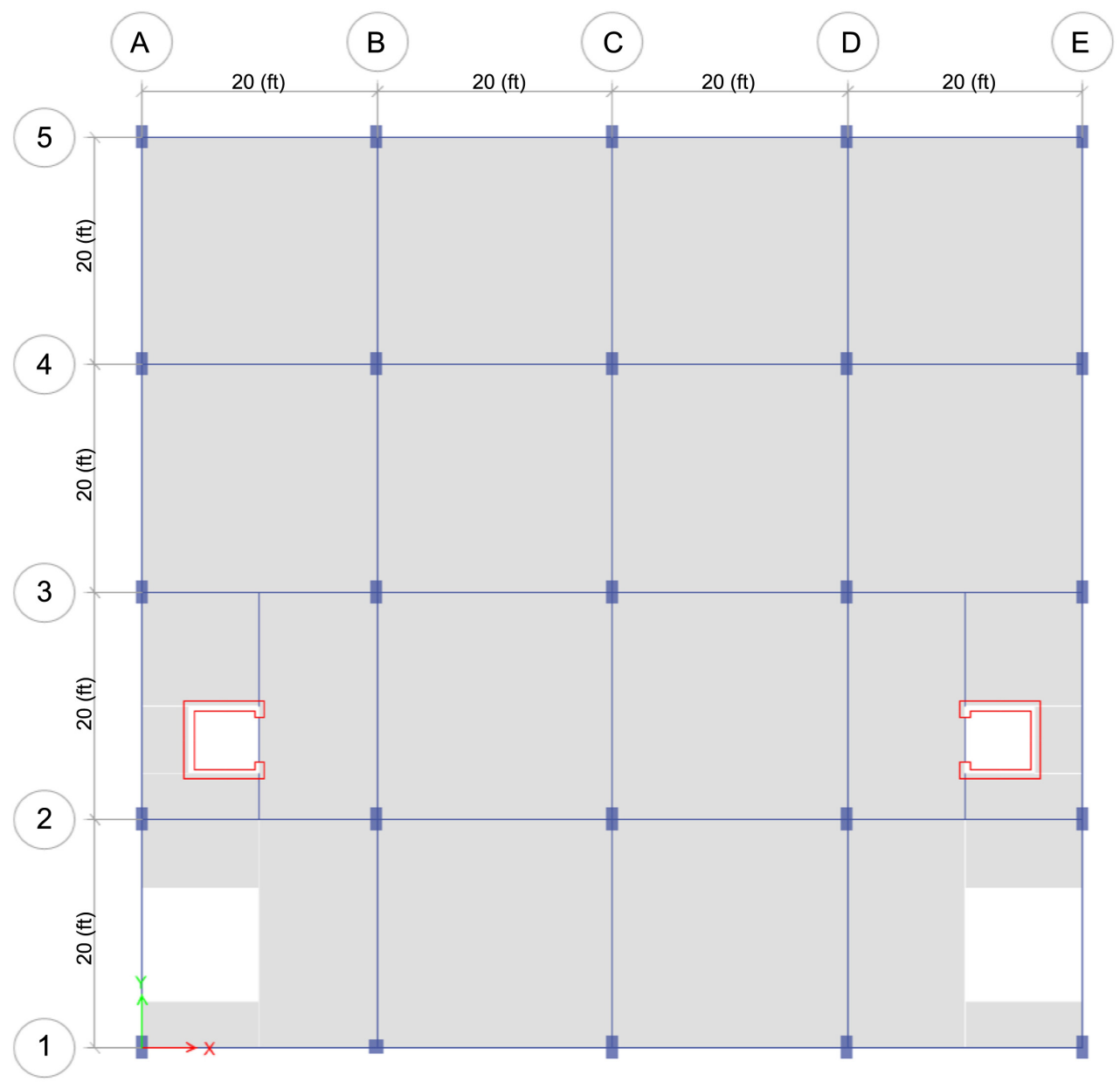

Figure 3. Plan view of model 1 (square shaped regular building).

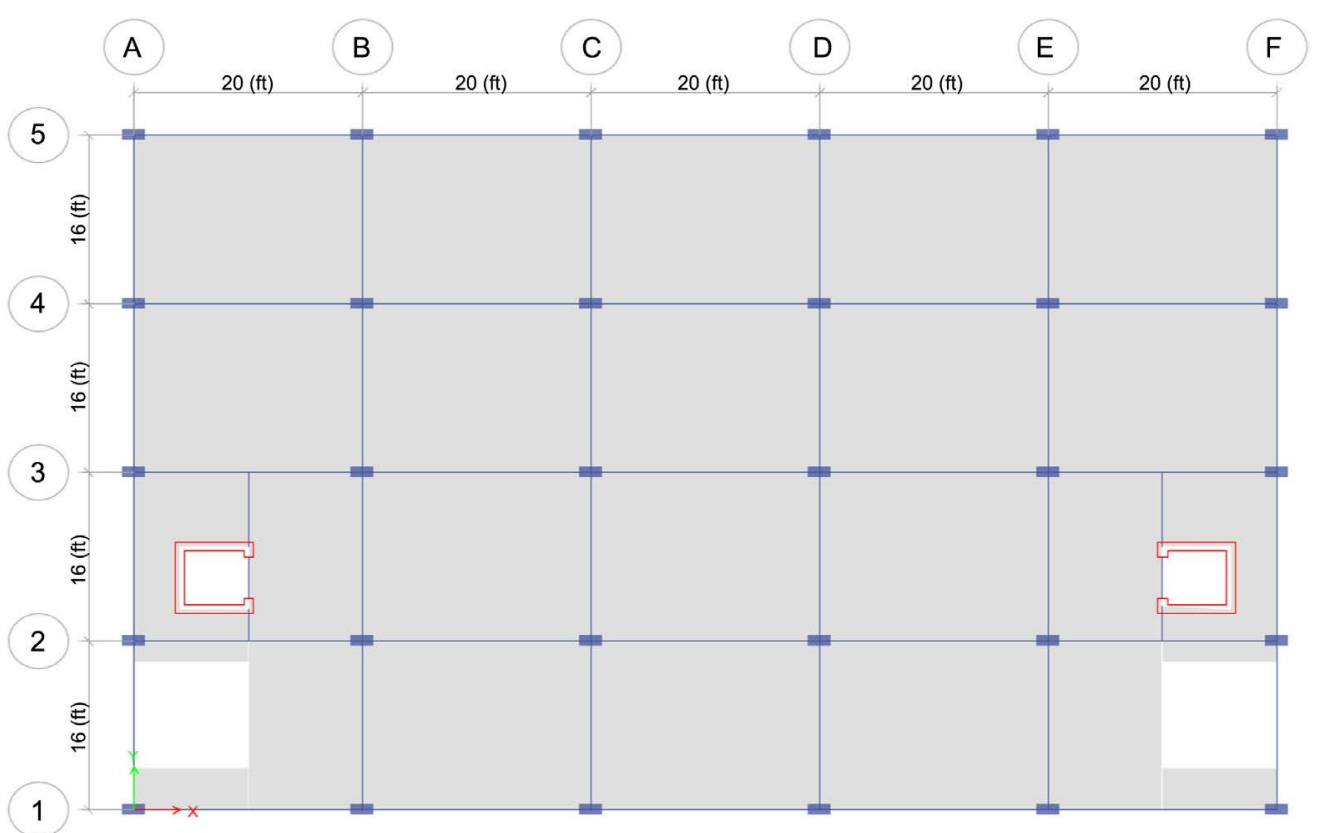

Figure 4. Plan view of model 2 (rectangular shaped regular building). 


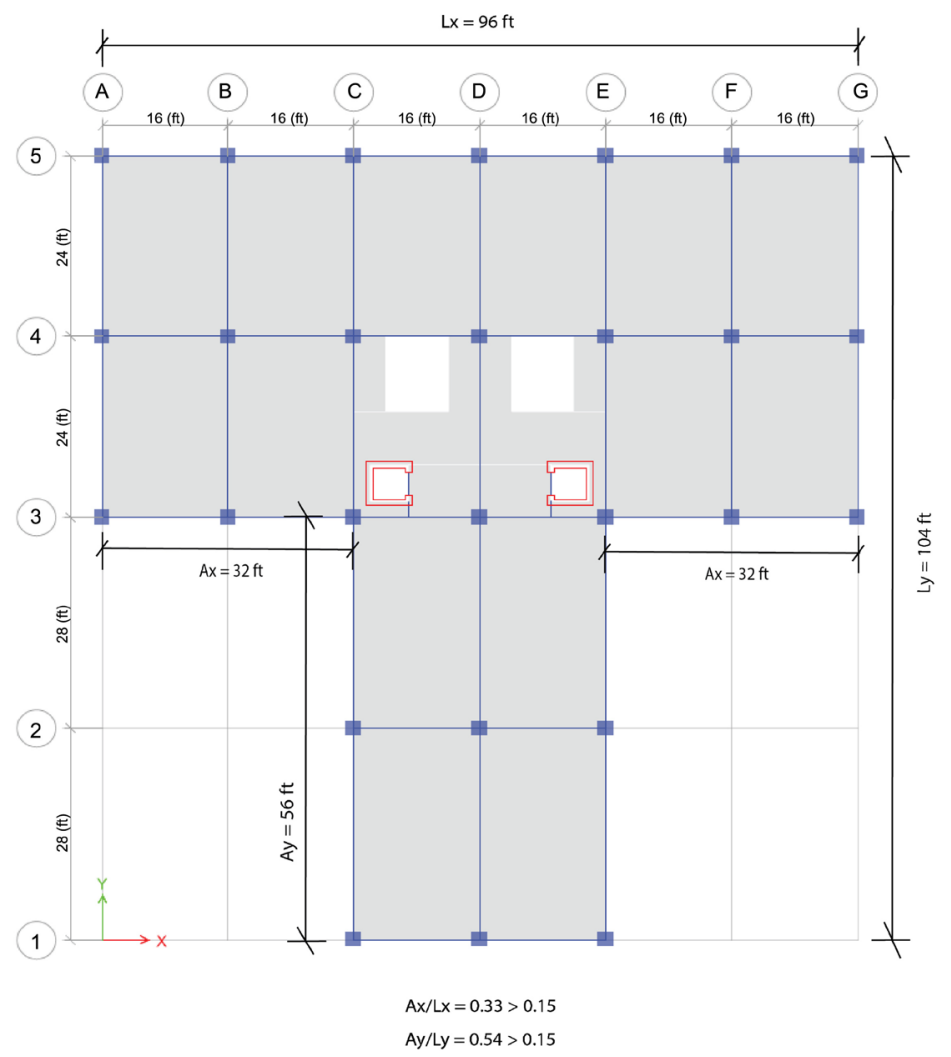

Figure 5. Plan view of model 3 (T shaped irregular building).

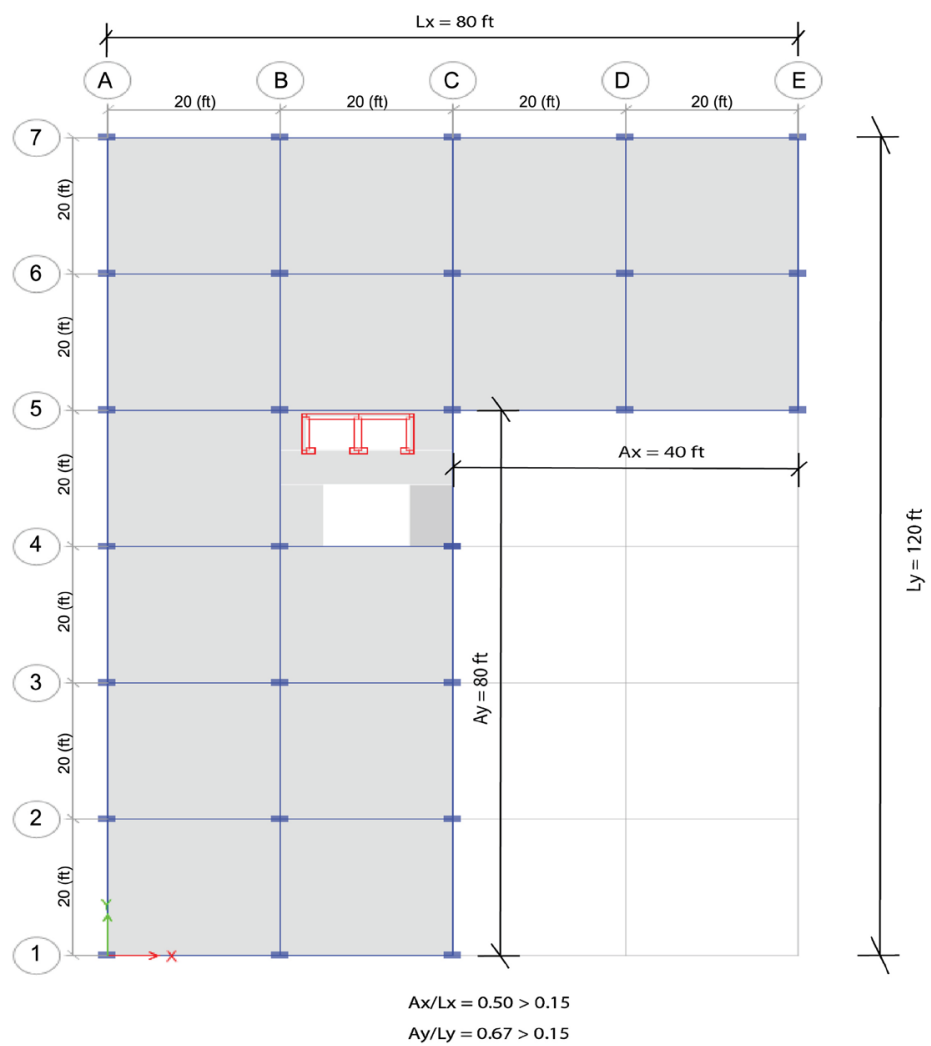

Figure 6. Plan view of model 4 (L shaped irregular building). 


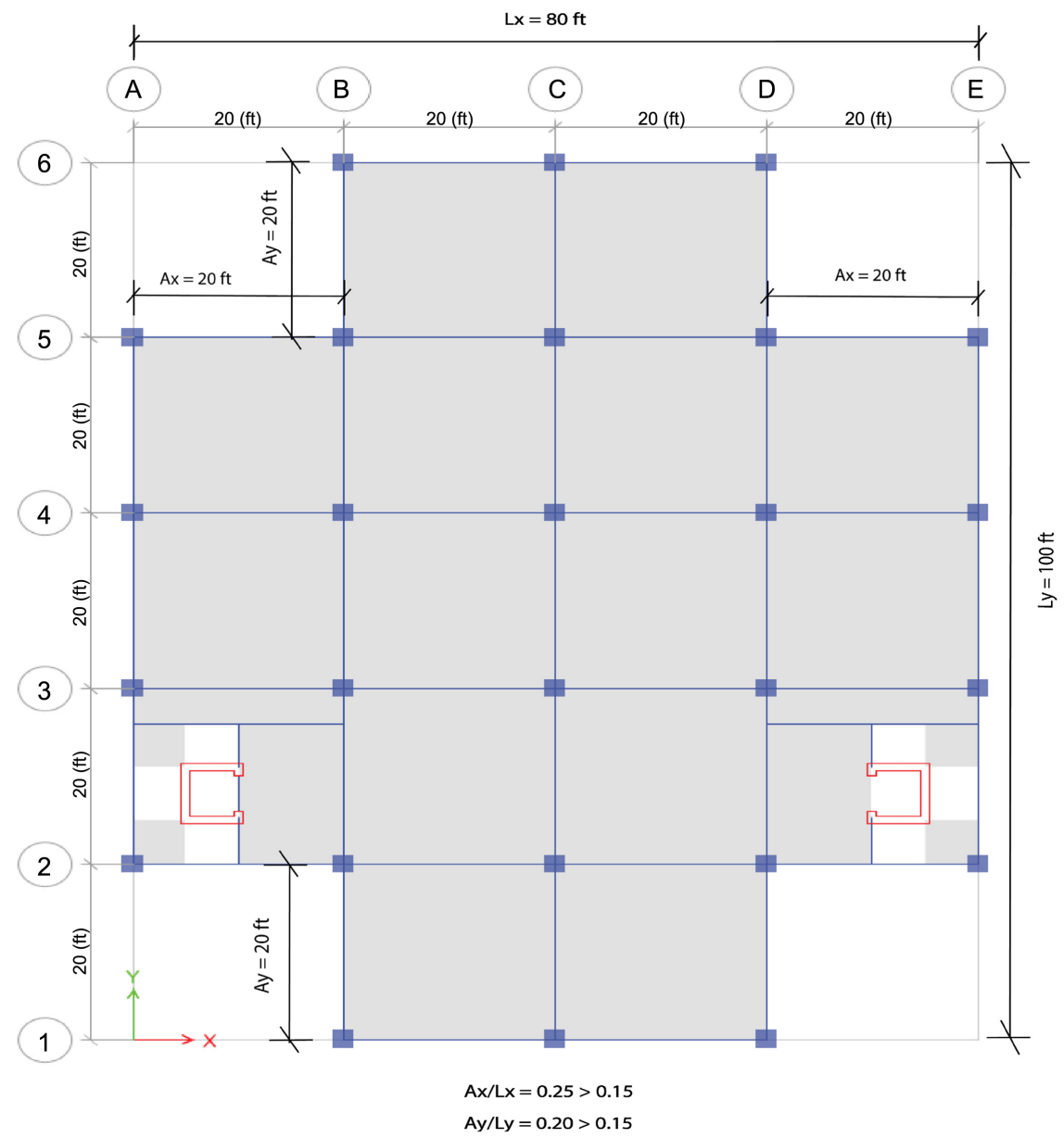

Figure 7. Plan view of model 5 (+ shaped irregular building).

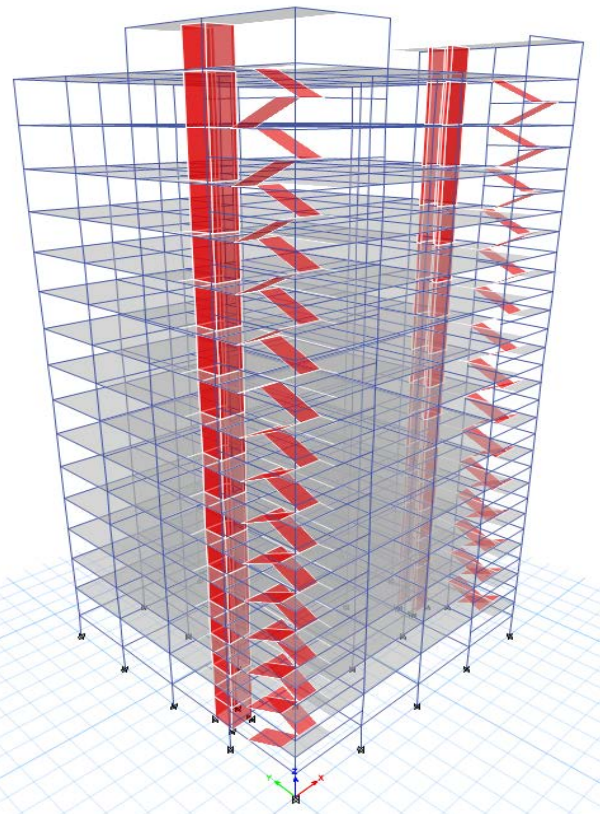

Figure 8. 3D view of model 1 . 


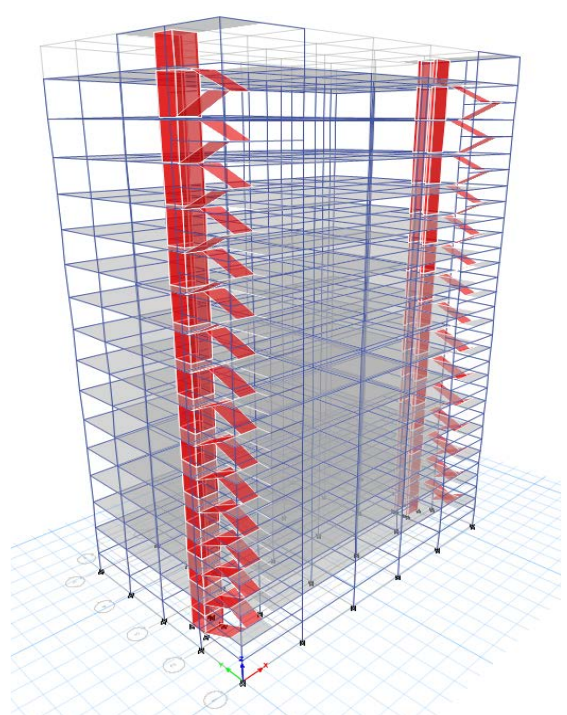

Figure 9. 3D view of model 2.

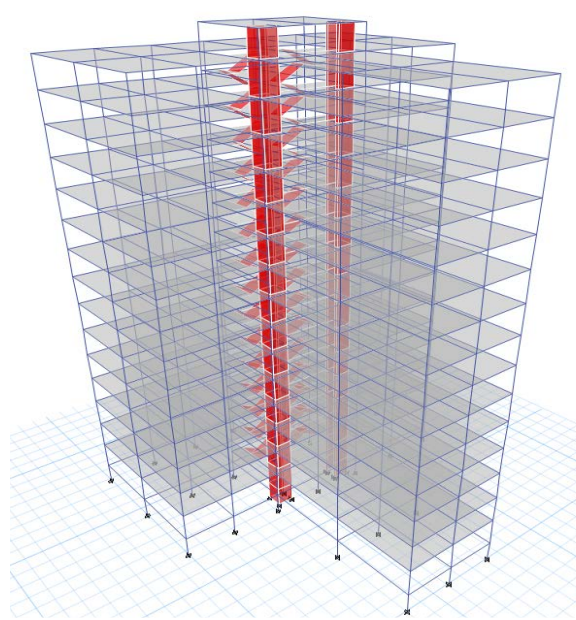

Figure 10. 3D view of model 3.

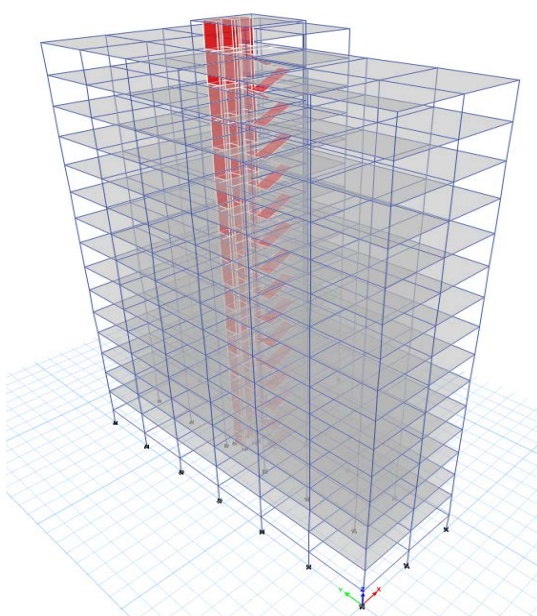

Figure 11. 3D view of model 4. 
The mass comparison among the 5 building models has been shown in Figure 13.

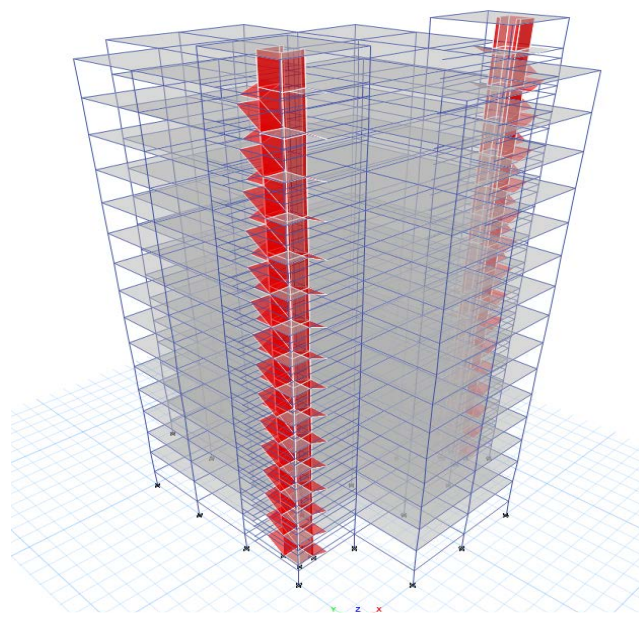

Figure 12. 3D view of model 5.

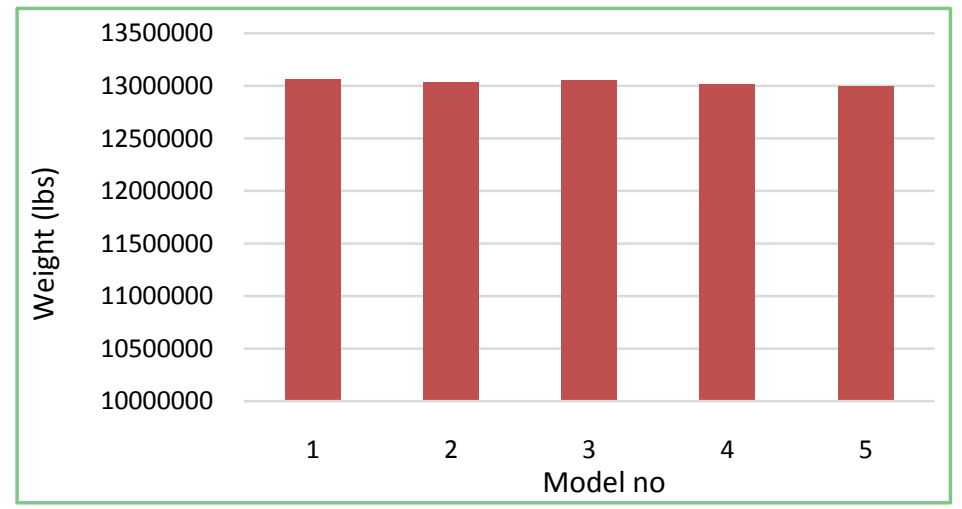

Figure 13. Mass comparison of 5 building models.

\section{Results and Discussions}

Graphical representations showing comparison among story displacement of the 5 building models for Seismic load (EQ), Wind load (WL) and dynamic response spectrum (RS) for both $\mathrm{X}$ and $\mathrm{Y}$ axis are discussed below.

Displacement of stories for earthquake loads in $\mathrm{X}$ and $\mathrm{Y}$ direction has been shown using equivalent static analysis in Figure 14 and Figure 15 respectively for the 5 models. Displacement increases with the height of the building. For EQ (X direction) maximum displacement is 9.0222 inches at story 15 for model 5 which is 1.29 times more than the minimum displacement for model 2 at the same story. For EQ (Y direction), $\mathrm{T}$ shaped model 3 has the maximum displacement of 8.7564 inches at story 15 and rectangular building model 2 has the minimum displacement of 5.555 inches. In both directions, model 2 has the least displacement for earthquake loads and is hence the safest. Overall, irregular buildings having re-entrant corner irregularity have much more displacement 
value in comparison to regular buildings for earthquake loads.

Displacement of stories for wind load in $\mathrm{X}$ and $\mathrm{Y}$ direction has been shown using equivalent static analysis in Figure 16 and Figure 17 respectively for the 5 building models. $\mathrm{L}$ shaped building model 4 has the most displacement value in both cases. Figure 16 shows that the maximum value is 8.6875 inches for model 4 which is 3.05 times the minimum value for model 2. In case of WL (Y direction), the maximum value is 5.4235 inches where the minimum value is 2.7442 inches for square model 1. The displacement of model 2 for WL (Y direction) is higher than that of $\mathrm{X}$ direction because of its lesser dimension in that direction. Model 3 and model 4 show quite similar values but $\mathrm{L}$ shaped model is the most vulnerable in both directions.

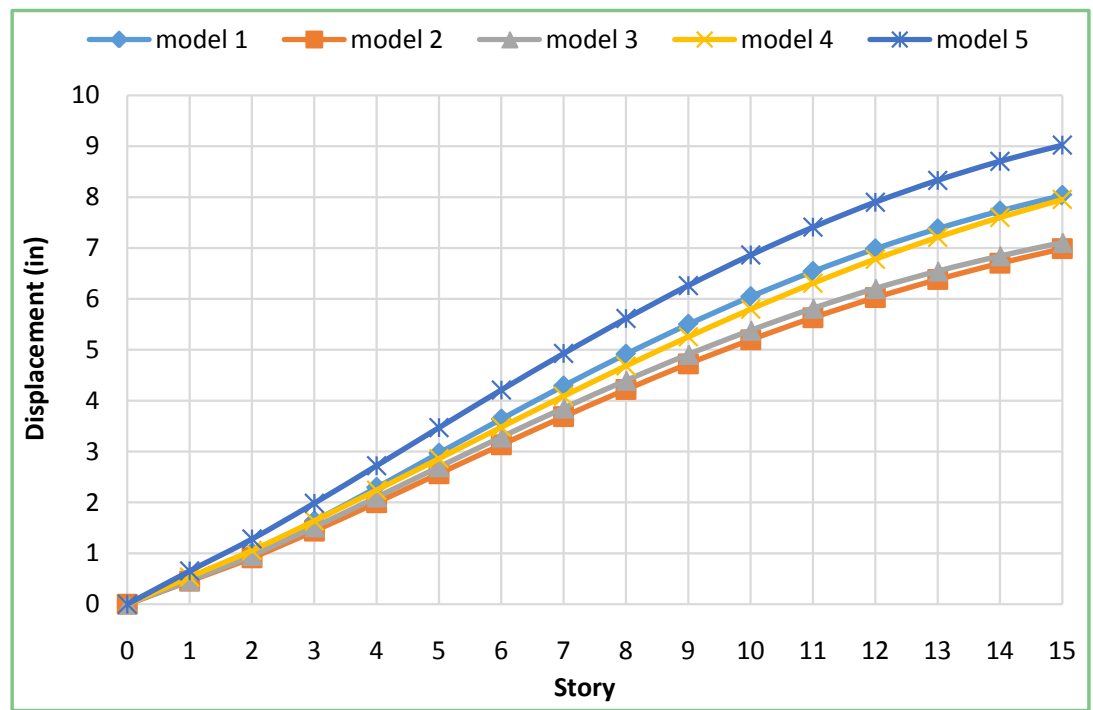

Figure 14. Story displacement for EQ (X direction).

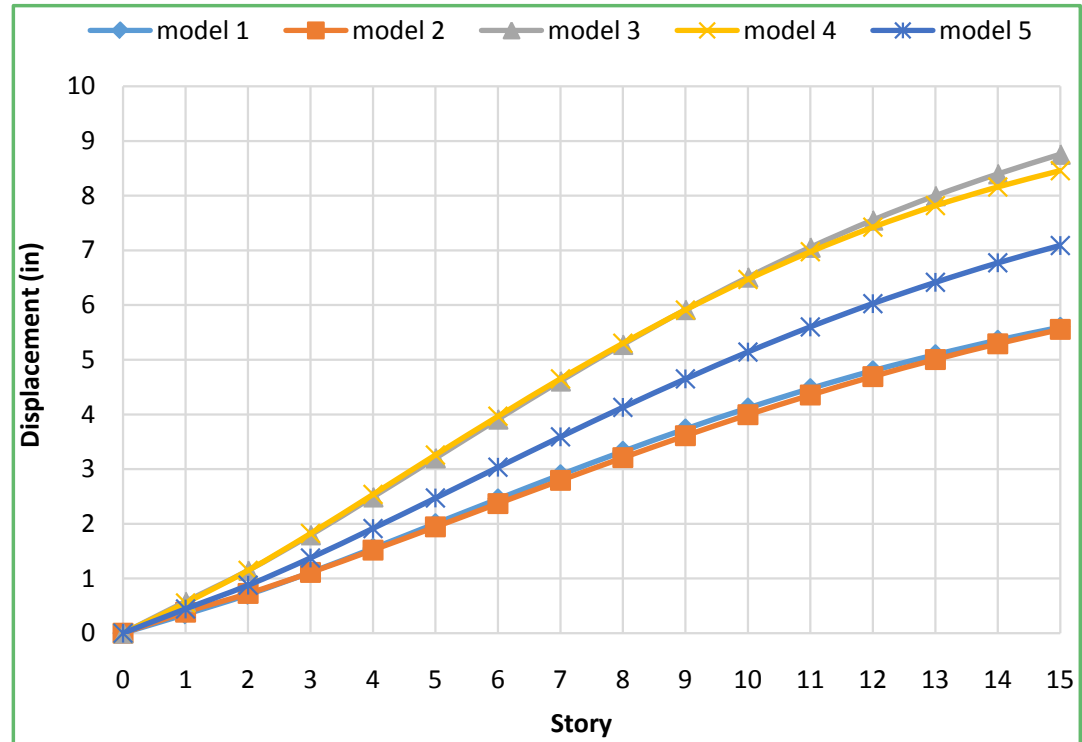

Figure 15. Story displacement for EQ (Y direction). 


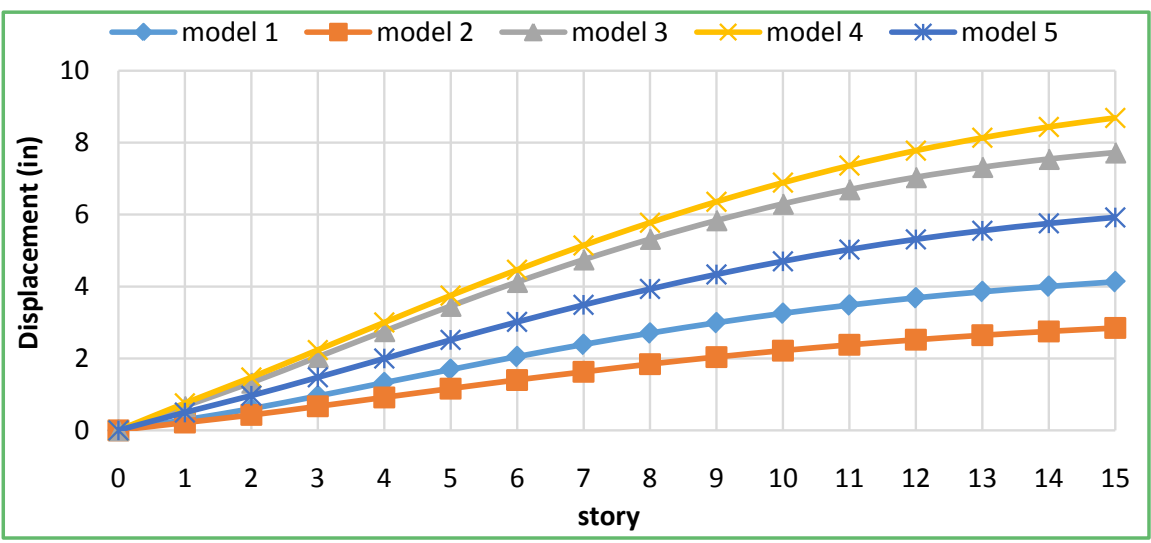

Figure 16. Story displacement for WL (X direction).

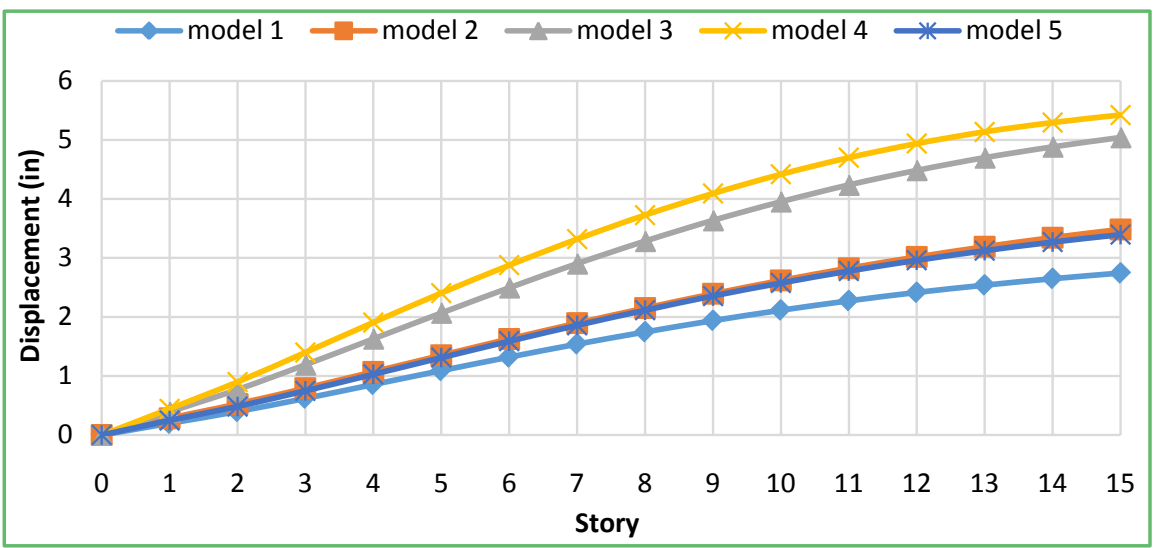

Figure 17. Story displacement for WL (Y direction).

Displacement of stories using response spectrum analysis has been shown in Figure 18 for the models. The maximum value of 11.3175 inches is obtained for + shaped building model 5 which is almost 1.7 times the minimum value of 6.6757 inches for model 2. It can also be seen that displacement values of irregular buildings are much higher than regular buildings.

A comparison of base shear for RS along $\mathrm{X}$ and $\mathrm{Y}$ direction among the 5 building models is shown in Figure 19 and Figure 20 respectively.

Irregularly shaped buildings have a higher base shear value in $\mathrm{X}$ direction for RS than compared to regular shapes. The maximum value is 1729 kip obtained for model 4 on the other hand the minimum value is 1406 kip for model 1. Whereas for $\mathrm{Y}$ direction, Base shear value for a regular shaped building is higher than irregular T, L and + shaped building. The maximum value is $1677 \mathrm{kip} \mathrm{ob-}$ tained for model 2 which is 1.18 times the minimum value obtained for $\mathrm{T}$ shaped model 3. M. A. Farhan and J. Bomisetty (2019) also found out the maximum base shear for regular building which was 1.53 times more than the minimum base share value for $\mathrm{T}$ shaped building [8].

Story-wise drift value for RS max along $\mathrm{X}$ and $\mathrm{Y}$ direction have been shown in Figure 21 and Figure 22 respectively for all 5 models. In $\mathrm{X}$ direction, the maximum 


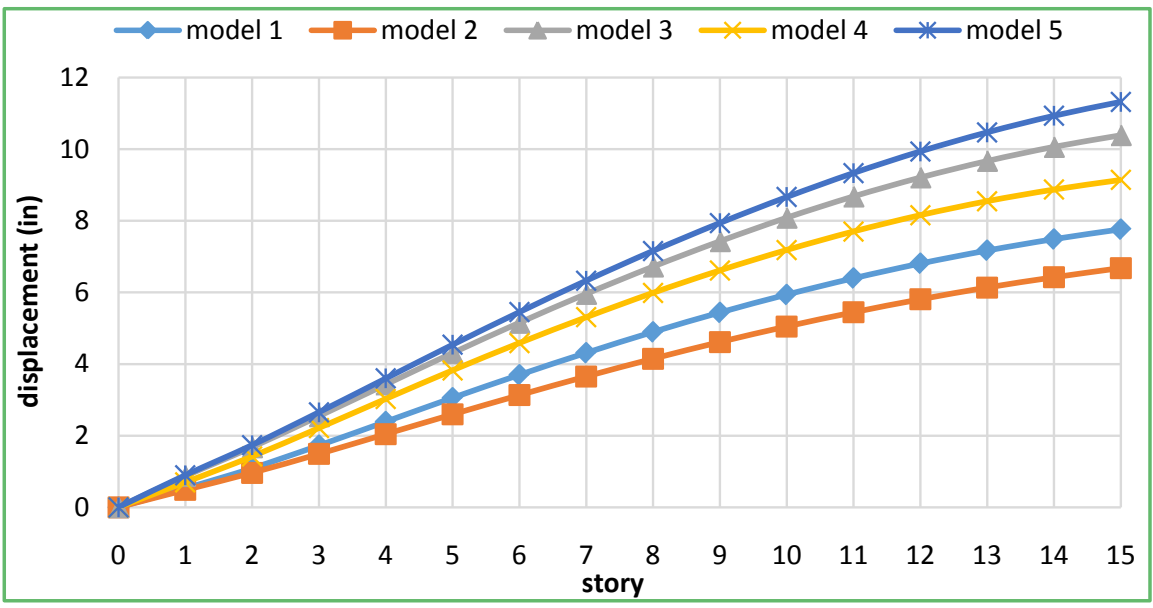

Figure 18. Story displacement for RS max.

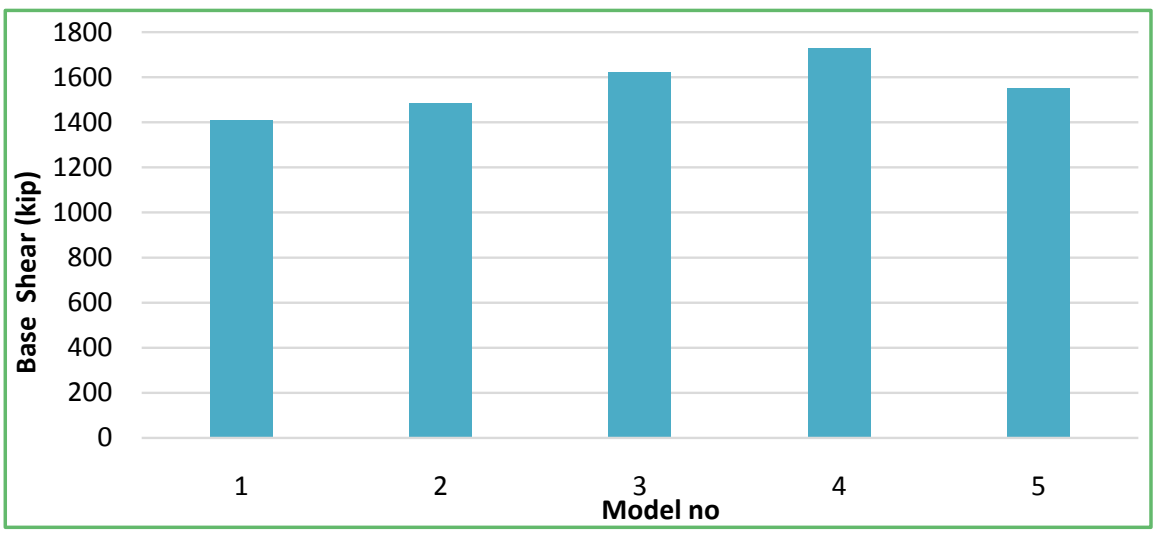

Figure 19. Base shear for RS max (X direction).

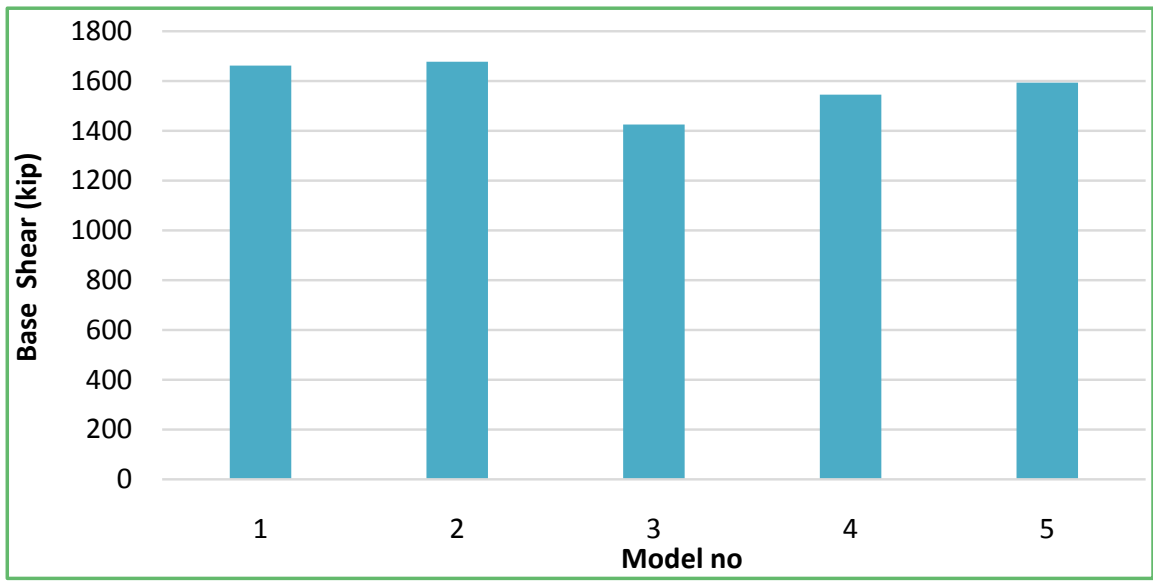

Figure 20. Base shear for RS max (Y direction).

value is 0.007952 for model 5 and in Y direction, maximum value is 0.007447 obtained for model 3. Rectangular model has the least value in both directions which is 0.00466 in $\mathrm{X}$ direction and 0.004197 in Y direction.

Figure 23 shows the comparison of time period among the taken building 


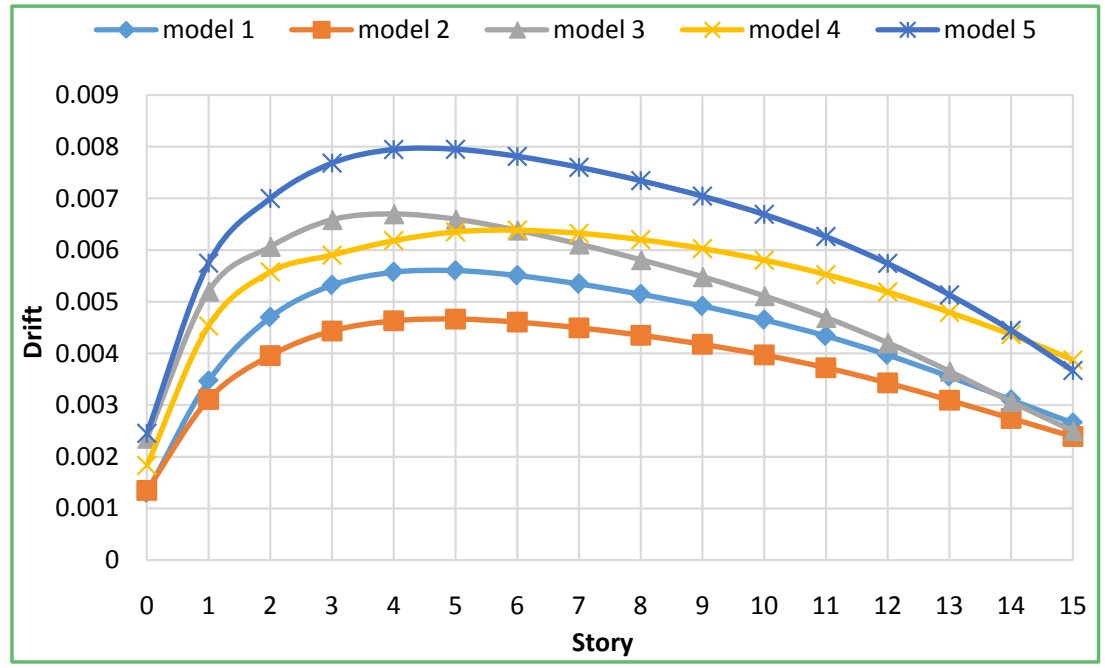

Figure 21. Story drift for RS max (X direction).

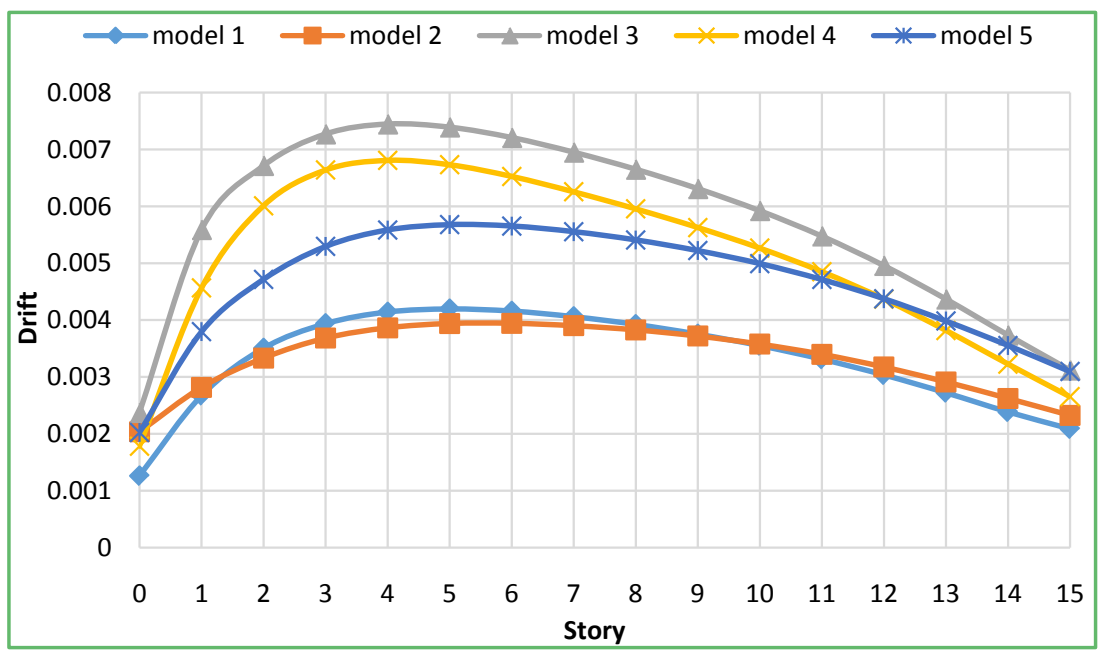

Figure 22. Story drift for RS max (Y direction).

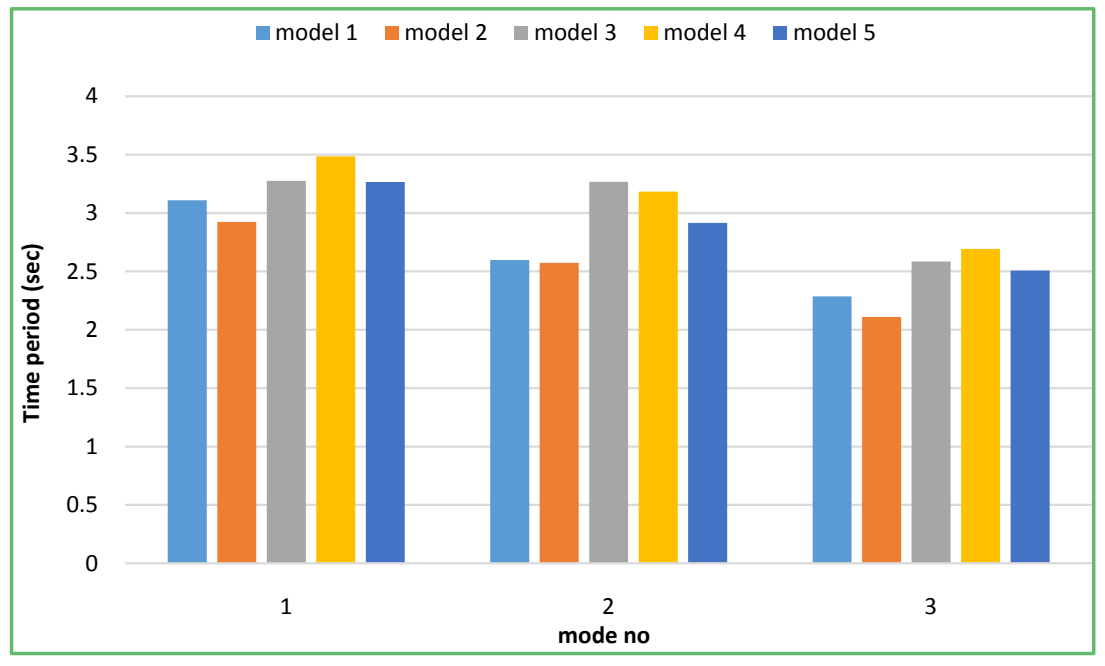

Figure 23. Maximum modal time periods (3 modes shown). 
models. The comparison is done taking 3 modes. For mode 1 , maximum value is 3.485 seconds obtained for model 4 and the minimum value is 2.923 seconds obtained for model 2. For mode 2, model 3 shows the maximum value of 3.267 seconds and model 2 shows the minimum value of 2.573 seconds. For mode 3, model 4 shows the maximum value of 2.692 seconds and model 2 shows the minimum value of 2.109 seconds. Time period for T, L and + shaped irregular buildings are almost the same.

\section{Conclusions}

The overall results of data can be summarized as follows:

- Building plans with re-entrant corner irregularity has a larger value of story displacement in comparison to regular building plans and thus are more vulnerable.

- Maximum displacement is obtained for response spectrum among all loads.

- Wind load has been a major concern for high rise buildings. Irregular buildings are more susceptible to wind loads than regular buildings.

- Rectangular model has the least value of displacement, story drift and time period and hence has the most chance of survival during a disaster.

- Rectangular building has a greater value of displacement for wind load along its smaller direction (Y direction is the model) than its larger dimension.

- + shaped building model has a greater value of displacement for seismic load and dynamic response spectrum.

- Base shear values are maximum in regular-shaped buildings in Y direction for dynamic response spectrum whereas irregular buildings show greater value in $\mathrm{X}$ direction. The most is seen for $\mathrm{L}$ shaped.

- Time period decreases preliminarily as the number of modes increases for all shapes.

- Irregular shaped buildings have a greater time period value compared to regular types.

- Story drifts for + shaped building has the maximum value in $\mathrm{X}$ direction and $\mathrm{T}$ shaped in $\mathrm{Y}$ direction. Rectangular building has the minimum in its larger direction.

- Story drift reaches the maximum value at story 4 and then it starts decreasing

\section{Conflicts of Interest}

The author declares no conflicts of interest regarding the publication of this paper.

\section{References}

[1] Earthquake Risk in Bangladesh. American Museum of Natural History, Student Version.

[2] Dhaka Population (2020) World Population Review. https://worldpopulationreview.com/world-cities/dhaka-population 
[3] Earthquake Track (2020) Recent Earthquakes Near Bangladesh. https://earthquaketrack.com/quakes/2020-04-16-11-45-23-utc-5-9-10

[4] The Daily Star (2013) Dhaka among 20 Cities Most Vulnerable to Quakes. https://www.thedailystar.net/news/dhaka-among-20-cities-vulnerable-to-quakes

[5] Ravikumar, C., et al. (2012) Effect of Irregular Configurations on Seismic Vulnerability of RC Buildings. Architecture Research, 2, 20-26. https://doi.org/10.5923/j.arch.20120203.01

[6] Kabir, M., Sen, D. and Islam, M. (2015) Response of Multi-Storey Regular and Irregular Buildings of Identical Weight under Static and Dynamic Loading in Context of Bangladesh. International Journal of Civil and Structural Engineering, 5, 252-260.

[7] Haque, M., Ray, S., Chakraborty, A., Elias, M. and Alam, I. (2016) Seismic Performance Analysis of RCC Multi-Storied Buildings with Plan Irregularity. American Journal of Civil Engineering, 4, 68-73. https://doi.org/10.11648/j.ajce.20160403.11

[8] Farhan, M.A. and Bomisetty, J. (2019) Seismic Analysis of Multistoried RCC Buildings Regular and Irregular in Plan. International Journal of Engineering Research \& Technology (IJERT), 8, 115-121.

[9] Firoz, M. and Singh, S.K. (2019) Response Spectrum Analysis for Irregular Multi-Storey Structure in Seismic Zone V. 16th Symposium on Earthquake Engineering, 20-22 December 2019, IIT, India.

[10] BNBC, Bangladesh National Building Code (2006) Housing and Building Research Institute. Dhaka, Bangladesh. 